\title{
Sustainable Concrete Technology
}

\author{
Sim, J. ${ }^{*}$ and Lee, K.H. ${ }^{1}$
}

\begin{abstract}
The growing concern over global warming and significant ecological changes requires sustainable development in all fields of science and technology. Concrete not only consumes huge amount of energy and natural sources, but also emits large amount of $\mathrm{CO}_{2}$, mainly due to the production of cement. It is evident that such large amount of concrete production has put significant impact on the energy, resource, environment, and ecology of the society. Hence, how to develop the concrete technology in a sustainable way has become a significant issue. In this paper, some of Korean researches for sustainable development of concrete are presented. These are sustainable strengthening for deteriorated concrete structure, sustainable reinforcement of new concrete structure, sustainable concrete using recycled aggregate and supplementary cementing materials and finally application of each technique to precast concrete.
\end{abstract}

Keywords: Sustainable development; FRP strengthening; recycled aggregate; industrial by-product; FRP reinforcement.

\section{Introduction}

Sustainable development is the organizing principle for sustaining finite resources necessary to provide for the needs of future generations of life on the earth. It is a process that envisions a desirable future state for human societies in which living conditions and resource-use continue to meet human needs without undermining the "integrity, stability and beauty" of natural biotic systems [1].

The concept of sustainable development is derived most strongly from the 1987 Brundtland Report. In 1987, the United Nations World Commission on Environment and Development released the report 'Our Common Future', commonly called the Brundtland Report. This report included what is now one of the most widely recognized definitions of sustainable development [1].

"Sustainable development is development that meets the needs of the present without compromising the ability of future generations to meet their own needs. It contains within it two key concepts:

* The concept of 'needs', in particular, the essential needs of the world's poor, to which overriding priority should be given; and

* The idea of limitations imposed by the state of technology and social organization on the environment's ability to meet present and future needs."

Concrete is the widely used construction material. The principal binder of concrete is cement, which was produced 4.3 billion tonnes in 2014 and global

1Department of Civil and Environmental Engineering, Hanyang University, SOUTH KOREA.

*Corresponding author; Email: jssim@hanyang.ac.kr production of cement has steadily increased, as shown in Figures 1 and 2 [2]. The production of cement is a major contributor to greenhouse gas emissions. Thus, concrete industry significantly impacts the ecology of our planet. How to develop concrete technology in a sustainable way becomes an urgent issue in the world even in Korea. Green house gases is major factor to global climate change. Korea is the $9^{\text {th }}$ largest producer of green house gases, which is $1.75 \%$ of global $\mathrm{CO}_{2}$ emissions in 2014 , as shown in Figure 3 [3].

Currently, researches on sustainable development on concrete have been carried out on following aspects: extension of service life of concrete structure and development of low-carbon concrete material and structure. In this paper, therefore, some sustainable concrete technologies, which have proceeded in Korea, are presented by following three categories: strengthening technique of existing concrete structure, sustainable concrete, and sustainable reinforcement.

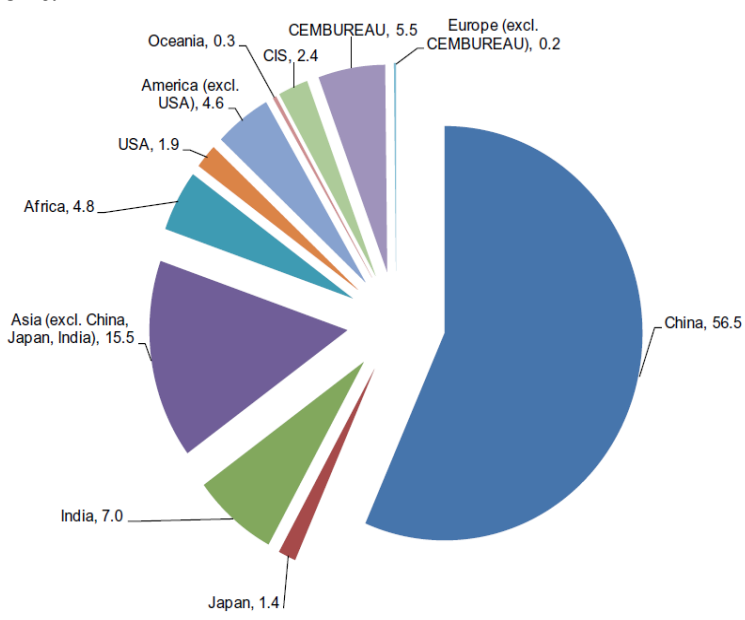

Figure 1. World Cement Production 2014, by Region and Main Countries (\%) [2] 


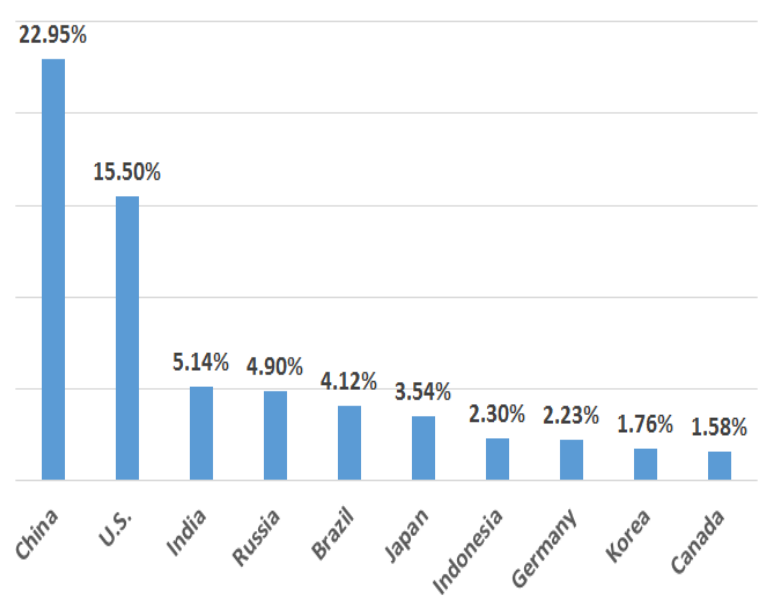

Figure 2. The 10 Largest $\mathrm{CO}_{2}$ Emitters 2014 [3]

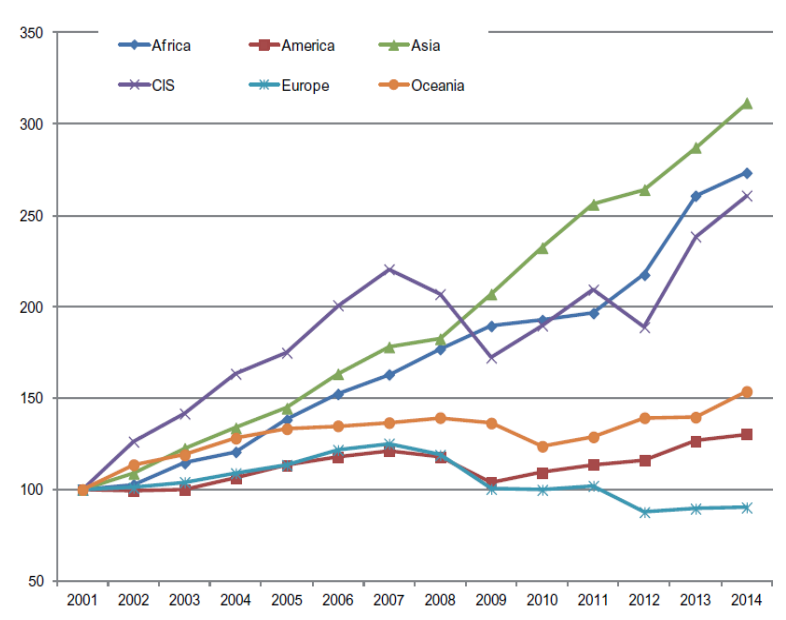

Figure 3. World Cement Production by Region - Evolution 2001 2014 (index: 2001=100) [2]

\section{Strengthening Technique of Existing Concrete Structure}

Deterioration by damage or aging of concrete structure causes declining of performance and durability. Deteriorated concrete structure needs strengthening, rehabilitation, reconstruction, or demolition to secure safety and serviceability of structure.

The strengthening is one of ways to extend a service life of concrete structure with minimum environmental, social and economic effects. For strengthening of concrete structure, steel plate has widely been used as conventional strengthening material. Steel, however, has presented weakness as strengthening material due to increasing of self-weight, corrosion, and limit of application. Using of FRP (Fiber Reinforced Polymer), therefore, as strengthening material is increasing. In these days, it is due to advantages of FRP such as high tensile strength, corrosion resistance, and lightweight. Figure 4 shows strengthening methods with steel and FRP.
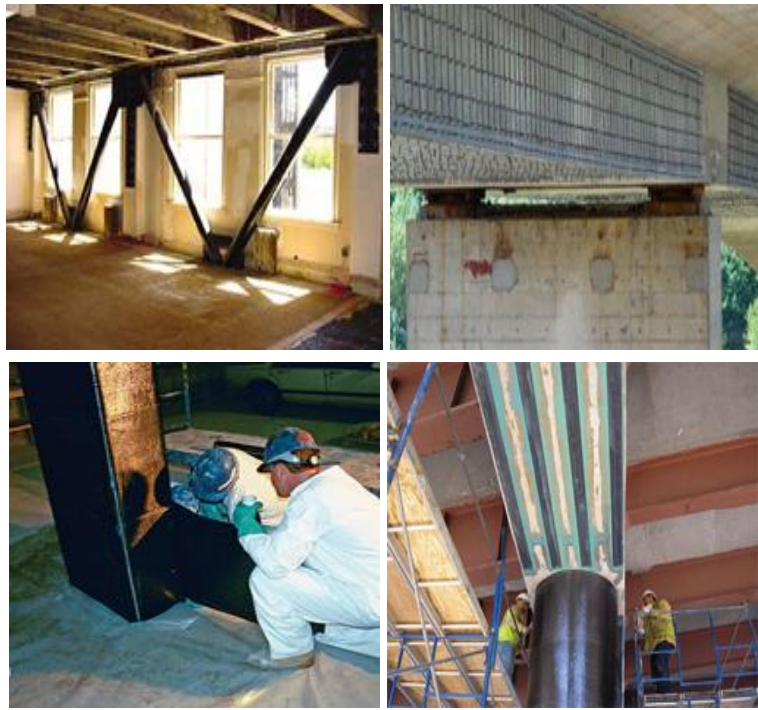

Figure 4. Strengthening of Concrete Structure with Steel and FRP

There are various types of FRP which are produced such as plate, sheet and rod type. Materials, like carbon, glass, aramid, basalt, bamboo, and plastic, are used for fiber of FRP product, which are shown in Figure 5.

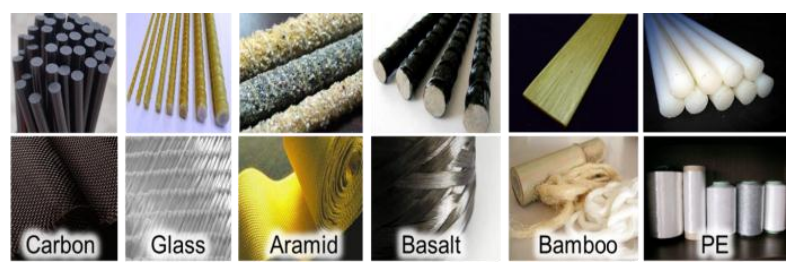

Figure 5. Types of Fibers for FRP [4-8]

\section{Externally Bonded Reinforcement (EBR)}

Steel plate bonding and column jacketing are the conventional methods of external strengthening. Steel plates bonded to the tension zones of concrete members have shown to be increasing the flexural capacity of the members [9]. This conventional method has been used over the world to strengthen bridges and buildings. However, the corrosion of steel plates, deterioration of the bond between steel and concrete, installation difficulties such as necessity of heavy equipment in installing have been identified as major drawbacks of these techniques. As a result researchers investigated FRP strengthening as an alternative to this method [10].

There are a number of applications of FRP as the strengthening material of reinforced concrete structure. The externally bonded reinforcement (EBR) is typical strengthening method using FRP. Figure 6 shows how to apply EBR to concrete structures. FRP plates or strips can be bonded to the external surface of concrete members thus increasing the flexural 
or/and shear strength of the members. FRP fabrics or sheets can be wrapped around reinforced concrete columns thus increasing the confinement and the axial strength. Furthermore it increases the flexural, shear and torsion strengths and improves the ductility [10].
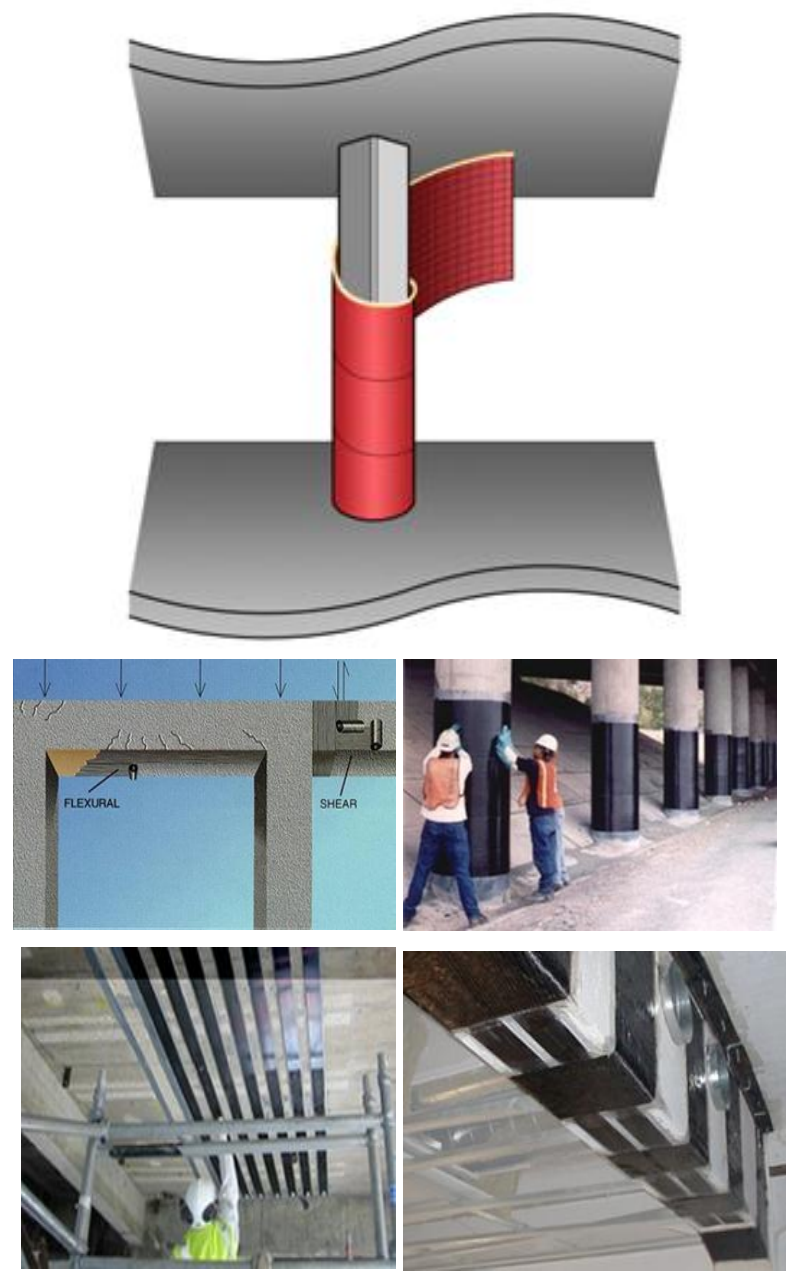

Figure 6. Externally Bonded FRP Systems [11,12]

\section{Near Surface Mounted (NSM) Method}

The externally bonded reinforcement has showed several drawbacks which are early debonding of FRP and not fully showing tensile characteristic of FRP strengthening material [13]. Therefore, embedding of strengthening material, Near Surface Mounted (NSM) method, which is shown in Figure 7, was suggested to supplement such drawbacks of externally bonded reinforcement. The NSM method could improve bonding performance between structural member and strengthening material by embedding FRP strengthening material so it could effectively not only transfer stress but also prevent early debonding. Consequently, tensile property of FRP reinforcement can be expected to be effectively shown [14].
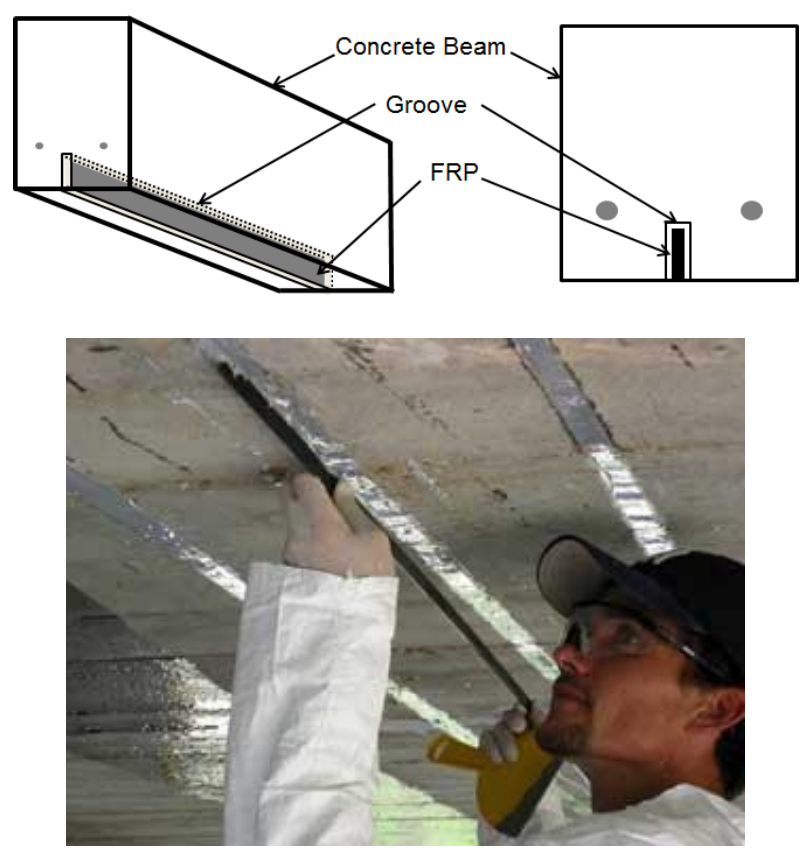

Figure 7. Near Surface Mounted (NSM) Strengthening Method [5]

\section{Sustainable Concrete}

\section{Recycled Aggregate}

In the last decade, amount of construction waste has been considerably increased due to the demolition of old structures, re-construction of buildings, improvement of the living standard, etc. Also, the reserves of natural aggregate for construction become depleted rapidly. Social and environmental pressures, therefore, on the construction wastes drive greater significance on the recycling of the waste. The application of recycled concrete aggregate (RCA) has sometimes been limited in the practice and remained in the lowvalued purposes only such as road base materials. Primary reasons may include negative understandings of concrete engineers on the quality and performance of RCA and concrete using RCA, as well as unstable supply of waste to the recycling facilities leading to unpredictable deliveries of final RCA. In the past the recycling technique was not satisfactory to produce a good quality RCA with appropriate economic efficiency. There has been, however, a great improvement in the recycling technique to produce RCA of which quality is close to natural aggregate [15].

There were some techniques how to produce recycled aggregate with high quality, including (1) mechanical grinding which is shown in Figure 8 [15]; (2) heating and grinding (Figure 9) [16], and (3) acid treatment [17]. In this paper, study on recylced aggregate with acid treatment is presented. 

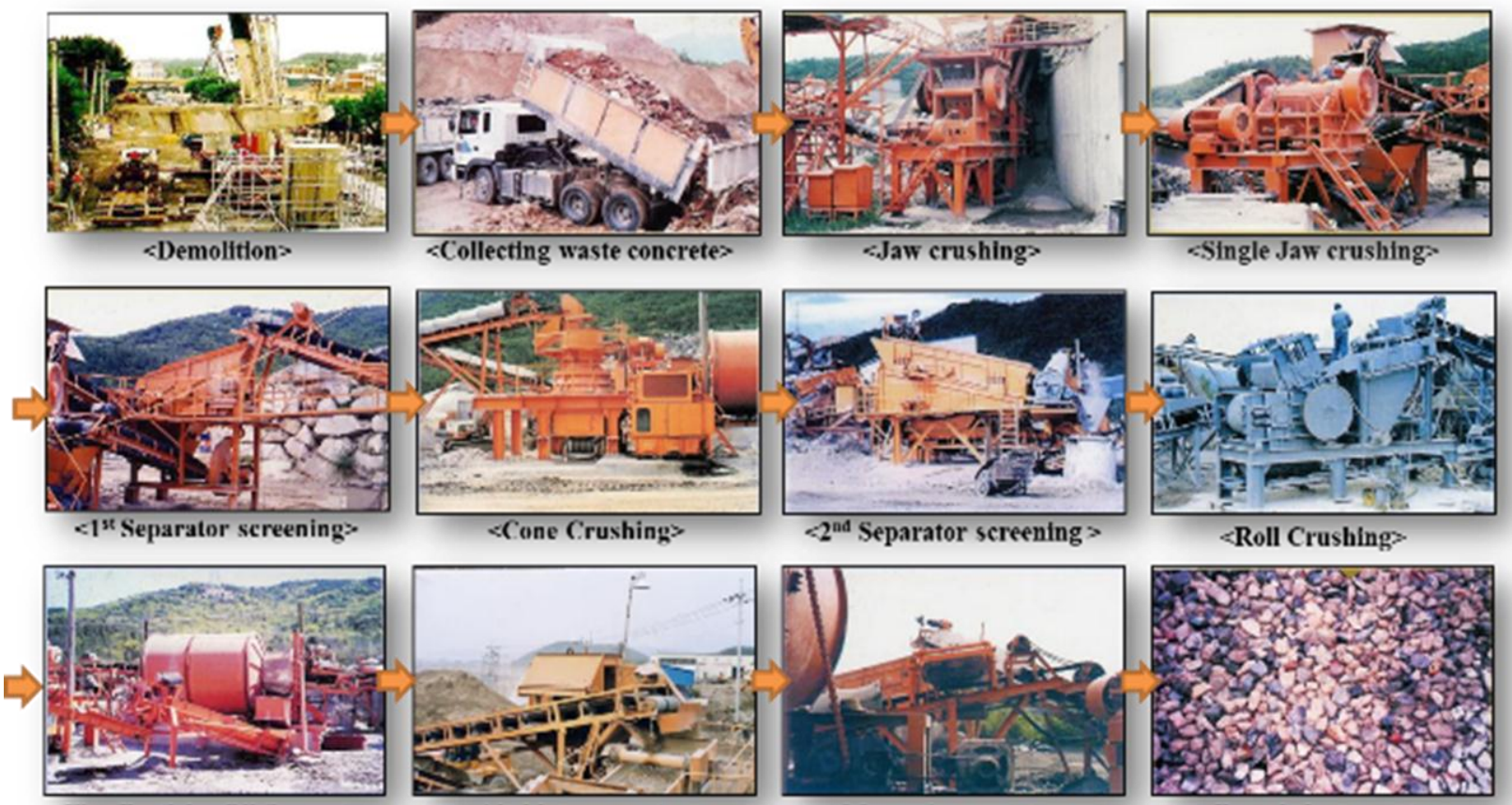

Fine Particles Oil Seperator

$<$ Air blow separator?

$<$ Magnetic separators

- Recycled aggregates

Figure 8. Production Process of Recycled Aggregate [15]

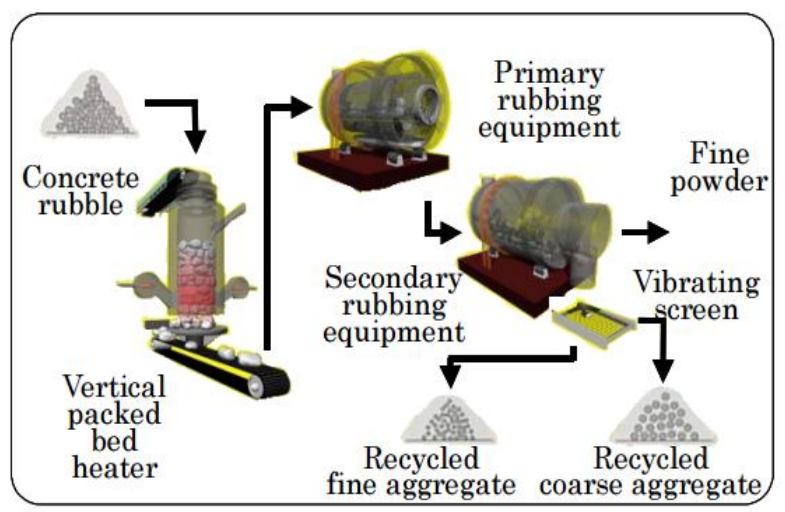

Figure 9. Process of Aggregate Refining by Heating and Grinding Method [16]

\section{Recycled Aggregate with Acid Treatment}

Natural aggregate was used for production of control mix. The maximum size of natural coarse aggregate was $25 \mathrm{~mm}$ and in addition to well-graded natural fine aggregate was used for experimentation. Recycled aggregates was used with same condition as natural aggregate. Recycled aggregates were, however, contained impurities like bonded mortar. Therefore, it was proposed to remove the bonded mortar by acid ( $\mathrm{HCl})$ treatment so that its effect on compressive strength of concrete studied [17].

The compression test indicates that an increasing trend of compressive strength in the early age of the concrete specimens. However, it shows that strength of recycled aggregate specimens is lower as compared to natural aggregate specimens. Since the cement, mortar attached to the recycled aggregate is the major factor that weakens the mechanical behavior of concrete. Therefore, removal of attached mortar is necessary to improve their quality. Figure 10 shows a graphical representation of variation of compressive strength decreasing of each batch was analyzed. The main cause of the poorer quality of recycled aggregate is due to bonded mortar content that resulted in porous, high absorptive and cracks during the crushing of the concrete waste. Different concentration of hydrochloric acid has been used in this study to remove the bonded mortar content effectively. It shows that water absorption of the RCA has significantly reduced [17].

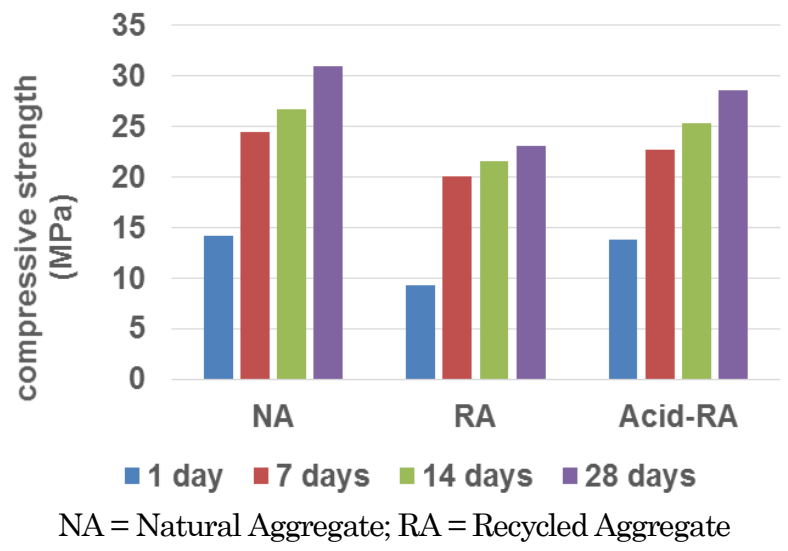

Figure 10. Comparison of Compressive Strength [17] 


\section{Concrete with Waste Glass Powder}

Supplementary cementing materials (SCMs) contribute to the properties of hardened concrete through hydraulic or pozzolanic activity. Typical examples are fly ashes, slag cement (ground, granulated blastfurnace slag), and silica fume. These can be used individually with portland or blended cement or in different combinations. Supplementary cementing materials are often added to concrete to make concrete mixtures more economical, reduce permeability, increase strength, or influence other concrete properties [18]. Demands and application of SCMs would increase due to decreasing of $\mathrm{CO}_{2}$ emission from cement producing as Figure 11 describing.

\section{$\mathrm{CO}_{2}$ emission}

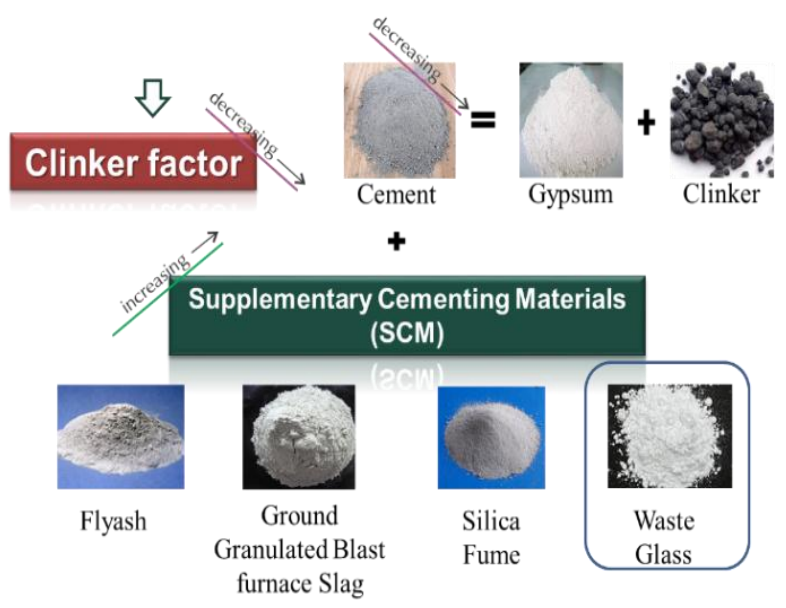

Figure 11. Using of SCM for Decreasing of $\mathrm{CO}_{2}$ Emission

Fly ash, the most commonly used pozzolan in concrete, is a by-product of thermal power generating stations. Commercially available fly ash is a finely divided residue that results from the combustion of pulverized coal and is carried from the combustion chamber of the furnace by exhaust gases.

Slag Cement, formerly referred to as ground granulated blast-furnace slag, is a glassy, granular material formed when molten iron blast-furnace slag is rapidly chilled - typically by water sprays or immersion in water - and subsequently ground to cement fineness. Slag cement is hydraulic and can be added to cement as an SCM.

Silica fume, also called condensed silica fume or microsilica, is a finely divided residue resulting from the production of elemental silicon or ferro-silicon alloys that is carried from the furnace by the exhaust gases. Silica fume, with or without fly ash or slag, is often used to make high-strength concrete.
Glass waste has an increasing importance as a new source of pozzolanic addition for the production of sustainable blended cements. Glass chemical composition and average fineness are very important parameters in view of physical and mechanical performances expected in the relevant binder [19]. Furthermore, recycling waste glass is an economical and eco-friendly source by a substitute for concrete and admixture. This study aims at evaluation of physical performances (i.e. flexural and compressive strength) of concrete depending on the ratio of waste glass ground granulated and fly ash to recycle it out of industrial by-products which is generated from domestic and international industry [20].

Using the following substitution ratios of waste glass powder $(5,10,20$, and $30 \%)$ and fly ash $(10 \%)$ to evaluate the application of waste glass powder. For comparison, a concrete mixture containing $20 \%$ fly ash as cement replacement was adopted as a control mixture, which is extensively used for concrete pavement on highways in Korea. Compressive strength test was performed on $100 \times 200 \mathrm{~mm}$ concrete cylinders according to ASTM C39. Strength of specimen was measured at 7 and 28 days after water curing temperature of $20 \pm 2^{\circ} \mathrm{C}$. Flexural strength test was performed using prismatic shape $150 \times 150$ $\times 550 \mathrm{~mm}$. Flexural strength test was performed according to 4-point flexural test method after water curing temperature of $20 \pm 2^{\circ} \mathrm{C}$. Test results are presented at Figure 12 [21].
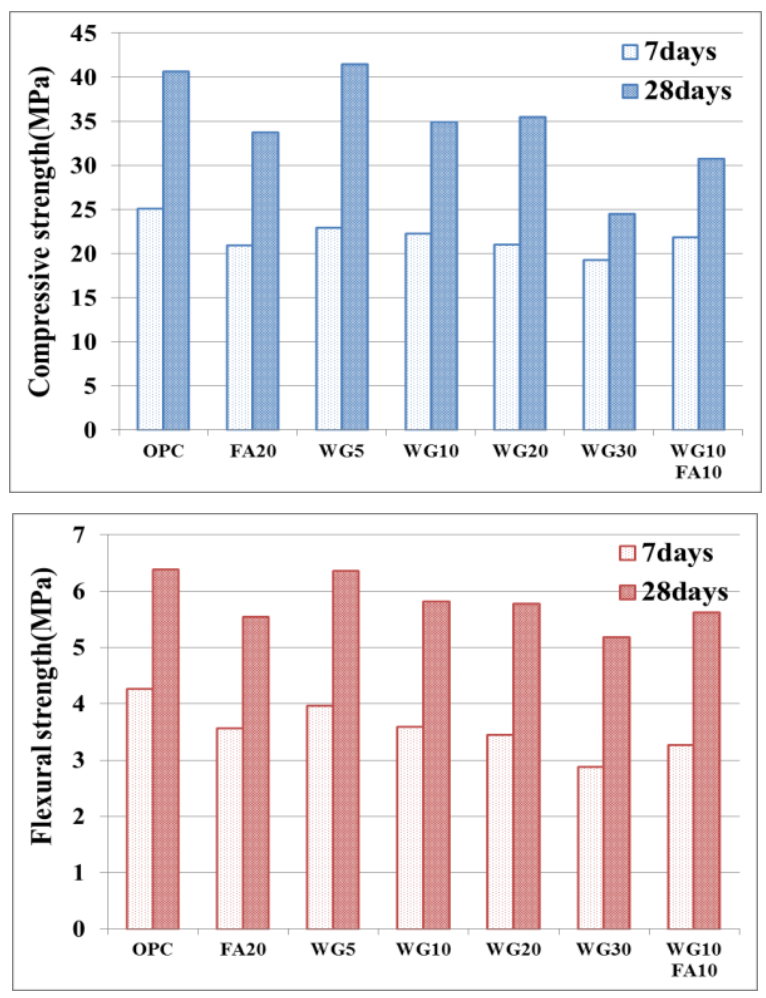

Figure 12. Compressive and Flexural Strength Results using Fly Ash (FA) and Waste Glass (WG) Powder [21] 


\section{The Results can be Summarized as Follows: [21]}

Compressive strength tests shows gradual decrease of the strength as the additives of waste glass powder increased. With the waste glass powder of $5 \%$, however; the strength shows the highest strength up to $102 \%$ compared with that of OPC.

As a result of the flexural strength tests all mixed cases except for the waste glass powder mixture of $30 \%$, exceeds the designed and mix flexural strength of $4.5 \mathrm{MPa}$ and of $5.4 \mathrm{MPa}$, respectively. According to the compressive strength test, the higher the mix rate of glass powder, the lower the resultant flexural strength.

\section{Sustainable Reinforcement}

Inevitably, traditional concrete structures with steel reinforcing bars gradually deteriorate, because of either external loading or severe environmental conditions, such as alkali reactions, de-icing salt, and freeze-thaw cycles. Degradation or deterioration in reinforced concrete members can lead to other serious structural damage, eventually causing structural failure. The most effective way to prevent corrosion is to use a reinforcing material that does not corrode [22]. Many studies have focused on developing new reinforcing materials, such as fibrereinforced polymers (FRPs), to solve the fundamental problems of steel rebar [23,24]. In reinforcedconcrete construction, FRP rebar is generally composed of organic fibres such as carbon and glass fibre or inorganic fibres such as aramid fibre, which are bonded together using a polymer resin such as polyester, vinyl-ester, or epoxy. Glass FRP (GFRP) constitutes the majority of $\mathrm{FRP} /$ polymer matrix composites because of its wide range of properties and lower cost. Commercial GFRP rebar is manufactured using a pultrusion process, which is suitable for the construction industry on account of its fast speed of operation, good quality, and relatively lowequipment cost. However, GFRP rebar, which is just pultruded, has plain surface. It will be not able to have enough bond capacity for reinforcement of concrete structure. The surface structures of GFRP rebar, therefore, used to enhance bonds with concrete are usually classified into one of three categories: braided patterns, sand-coated or deformed [25].

\section{GFRP Rebar with Ribs Containing Milled Glass Fibers}

The bond of FRP rebar with shallow continuous fibers and rough particles depends primarily on chemical adhesion and friction. In contrast, the bond of FRP rebar with deformations like lugs or ribs depends primarily on the mechanical interaction with the surrounding concrete. The FRP rebar with ribs have been proved to be available on reinforcements in concrete structures by a number of experimental studies. The surface structure of C-bar, which is a representative ribbed GFRP rebar, is made with several of sheet molded compound (SMC). The use of SMC enables manufacturers to form curved shape of the rebars. It should be noted that SMC, which is composed of a resin, fibers, and calcium carbonate, has good formability and strength. A mixture of epoxy resin and milled glass fibers was tested and evaluated as a surface structure of GFRP rebars to enhance the bond with the concrete in this study. The milled glass fibers were produced by grinding the fiber glass into a powder form of cotton-like appearance, resulting in initial placing in fresh liquid epoxy. The milled glass fibers were utilized as a reinforcing material in order to improve formability and strength of the matrix in surface structure of GFRP rebar [25].

The glass fiber used is commercially available in the E-Glass formulation, which is the most widely used general purpose form of composite reinforcements. The milled glass fiber is one that is hammer-milled strands into small lengths. They are usually used to improve thermal properties and dimensional stability in the injection molding processes. The milled glass fibers used in this study were manufactured by a special order of the authors not commercially available in Korea. The surface structure analogous to the ribs of ordinary steel rebar was considered as shown in Figure 13. The rib height and spacing were preliminary determined by using best performing value of relative rib area and spacing-to-height ratio theory that was originally used for ordinary steel rebars. The spacing and height of a rib were finally determined to be $6 \mathrm{~mm}$ and $1.3 \mathrm{~mm}$, respectively [25].

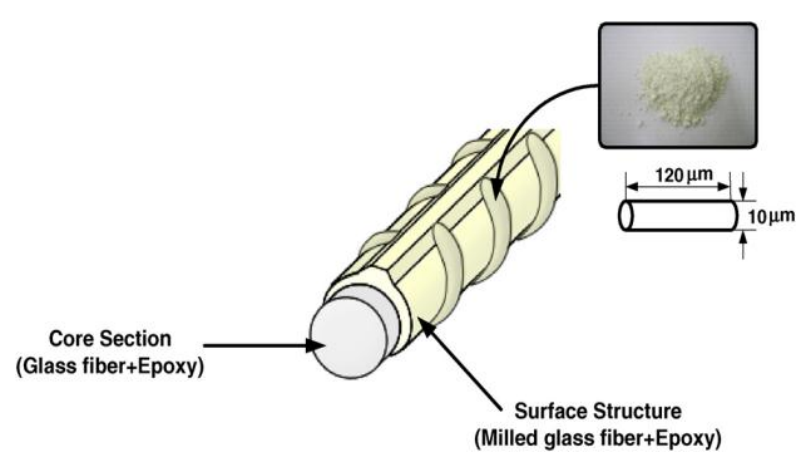

Figure 13. Schematic of the Proposed GFRP bar [26]

\section{Comparison of FRP Rebars by Pull-out Test}

This pull-out test is designed to evaluate bonding capacity of the proposed GFRP rebar with $50 \%$ of 
milled glass fibers and to be compared with other types of bars. The rebars tested herein have an approximately same diameter which is equivalent to No. 3 steel rebar. The specimens are designated according to their surface patterns: the proposed deformed GFRP rebar [PDGR]; the sand-coated GFRP rebar [SCR]; and the surface-braided GFRP rebar [SBR] of which surface is braided with glass fibers. In addition, an ordinary steel rebar is included and designated as [DS].

Table 1 describes the mechanical properties of rebars used in pull-out test. The bond strength $(\sigma b)$ was calculated in $\mathrm{MPa}$ according to the following formula:

$\sigma_{b}=\frac{P}{\pi l_{b} d_{b}}$

where, $\mathrm{P}$ is the pullout load in $\mathrm{N}, l_{b}$ is the embedded length in $\mathrm{mm}$, and $d_{b}$ is the nominal bar diameter in $\mathrm{mm}$ [26].

Applicability of a mixture with epoxy resin and milled glass fibers on a surface structure of GFRP rebar to enhance bond with concrete has been examined by several tests in this study. The mixture is successfully applied and shaped onto the GFRP composite bars when the amounts of milled fibers in the surface deformations are within 20-50\%. The bond strength of the GFRP rebar to concrete increases with the amount of the milled glass fibers and is better than that of other commercial GFRP rebars in Korea, and only 10\% less than that of the ordinary steel rebar. However, the amounts of the milled glass fibers in surface deformations have no significant effect on long-term durability of the GFRP rebar [26].

All of the three specimens for each variable failed in the mode of pullout and the average maximum bond strength is shown in Figure 14. The average maximum bond strengths of the GFRP rebars vary from $56 \%$ to $90 \%$ of that of the steel bar specimen. The bond strength of the SCR specimens is insignificantly low as compared to other types of GFRP rebar. This low bond strength is particularly due to low frictional resistance between the core and the surface structure. The bond strength of SBR is approximately $31 \%$ greater than that of SCR, and the proposed GFRP bar, PDGR, developed only 10\% less bond strength than the steel rebar, DS. From the test results, it can be concluded that the proposed GFRP rebar, which has ribs made of the mixture of the milled glass fiber and the epoxy, can provide sufficient bond strength to concrete [26].
Table 1. Summary and Mechanical Properties of Bars in Pull-out Test

\begin{tabular}{lccc}
\hline $\begin{array}{l}\text { An example of a } \\
\text { column heading }\end{array}$ & $\begin{array}{c}\text { Nominal } \\
\text { diameter }\end{array}$ & $\begin{array}{c}\text { Ultimate } \\
\text { strength } \\
(\mathrm{MPa})\end{array}$ & $\begin{array}{c}\text { Elastic } \\
\text { modulus } \\
(\mathrm{MPa})\end{array}$ \\
\hline $\mathrm{DS}$ & 9.5 & 660 & 200 \\
$\mathrm{PDGR}$ & 10.3 & 592 & 44.5 \\
$\mathrm{SBR}$ & 10.7 & 910 & 53.5 \\
$\mathrm{SCR}$ & 10.3 & 1000 & 34.8 \\
\hline
\end{tabular}

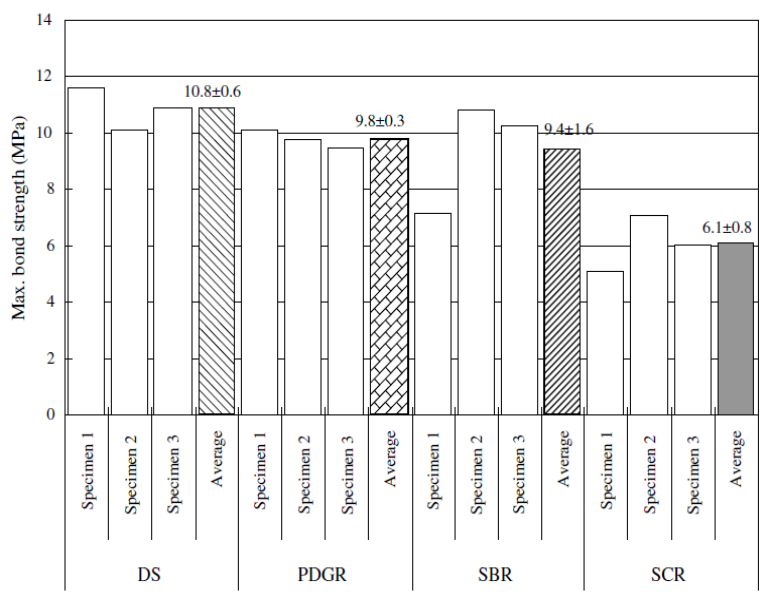

Figure 14. Results of Pull-out Test [26]

\section{Summary}

In this paper, scientific strategies for sustainable development of concrete in Korea, has been introduced as follows;

- Appropriate strengthening for deteriorated concrete structures with FRP,

- Recycling of construction wastes as coarse and fine aggregate by advanced producing process,

- Using industrial by-products as supplementary cementing materials,

- Fundamental prevention of reinforcement corrosion by using FRP rebar, and

These technologies could be applied to precast concrete to pursue sustainable development of concrete. Advantages of precast concrete with recycled aggregate are cost down on producing of precast concrete and enhancing of awareness on concrete using recycled aggregate. In addition, using of industrial by-product on precast concrete can enhance performance and durability of precast concrete products.

The achievements of these studies have contributed to sustainable development of concrete material and infrastructure, and further researches on their sustainable development features are positively necessary. 


\section{References}

1. World Commission on Environment and Development (1987). Our Common Future, Oxford: Oxford University.

2. Key facts \& Figures, the European Cement Association (http://www.cembureau.be).

3. Burck, J., Marten, F., and Bals, C., Climate Change Performance Index, Germanwatch and Climate Action Network Europe, 2014.

4. http://www.toray.com/

5. http://aslanfrp.com/

6. http://www.dostkimya.com/

7. http://www.technobasalt.com/

8. http://www.litrax.com/

9. Fleming, C.J. and King, G.E.M., The Development of Structural Adhesive for Three Original uses in South Africa, RILEM International Symposium, Synthetic Resins in Building Construction, Paris, 1967, pp.75-92.

10. CRC Construction Innovation, Review of Strengthening Techniques using Externally Bonded Fiber Reinforced Polymer Composites, CRC for Construction Innovation, Brisbane, 2002.

11. http://www.structuraltechnologies.com/

12. http://www.luckett-farley.com/

13. Spadea, G., Bencardino, F., and Swamy, R.N., Structural Behaviour of Composite RC Beams with Externally Bonded CFRP, Journal of Composites for Construction, 2(3), August, 1998, pp.132-137.

14. Täljsten, B., CFRP Strengthened-concrete Structures Strengthened with Near Surface Mounted CFRP Laminates, Proceeding of $3^{\text {rd }}$ International Conference on Composites in Infrastructure, San Francisco, California, June 10-12, 2002, pp.12.

15. Sim, J. and Park, C., Compressive Strength and Resistance to Chloride Ion Penetration and Carbonation of Recycled Aggregate Concrete with Varying Amount of Fly Ash and Fine Recycled Aggregate, Waste Management, 31, 2011, pp. 2352-2360.

16. Shima, H., Tateyashiki, H., Matsuhashi R., and Yoshida, Y., An Advanced Concrete Recycling Technology and Its Applicability Assessment through Input-output Analysis, Journal of Advanced Concrete Technology, 3(1), 2005, pp. 53-67.

17. Lee, H., Kim, Y., Shahid, M., Park, C., and Sim, J., A Study on the Compressive Strength of Recycled Aggregate Concrete Based on Bonded
Mortar Content, Proceedings of the $5^{\text {th }} A C F$ International Conference, Pattaya, Thailand, 2012, pp. 24-26.

18. Papadakis, V.G. and Tsimas, S., Supplementary Cementing Materials in Concrete Part I: Efficiency and Design, Cement and Concrete Research, 32, 2002, pp. 1525-1532.

19. Bignozzi, M.C. and Sandrolini, F., Effects of Different Glass Compositions on Eco-sustainable Blended Cements. In: Taylor \& Francis, Proceedings of the Conference Excellence in Concrete Construction through Innovation, Kingston University. Kingston upon Thames, UK, 2008.

20. Bignozzi, M.C., Saccani, A., Barbieri, L., and Lancellotti, I., Glass Waste as Supplementary Cementing Materials: The Effects of Glass Chemical Composition, Cement \& Concrete Composites, 55, 2014, pp. 45-52.

21. Lee, H., Jung, J., Oh, H., Zi, G., Sim, J., and Sim, J., Effect of Waste Glass Powder on Concrete Pavement, Proceedings of the $6^{\text {th }}$ ACF International Conference, Seoul, Korea, 2014, pp.21-24.

22. Treece, R. and Jirsa, J., Bond Strength of Epoxycoated Reinforcing Bars. ACI Mater. J., 86(2), 1989, pp. 167-174.

23. Vijay, P.V., Ganga Rao, H.V.S., and Krishnaswamy, V., Manufacturing, Durability and Bond Behavior of FRP Bars with Nanoclay. In Proceedings of the $7^{\text {th }}$ International Symposium on Fiber reinforced polymer (FRP) reinforcement for concrete structures (FRPRCS-7), Kansas City, Missouri, USA, 7-10 November 2005, pp. 77-98. (ACI SP-230).

24. Sim, J., Moon, D., and Oh, H., Bond Performance of Deformed GFRP Rebar with Milled Fibres to Concrete. In Proceedings of the 7th International Symposium on Fiber Reinforced Polymer (FRP) Reinforcement for Concrete Structures (FRPRCS-7), Kansas City, Missouri, USA, 7-10 November 2005, pp. 1497-1514. (ACI SP230).

25. Moon, D., Sim, J., and Oh, H., Experimental Characterization of the Bond Performance of a New Type of Glass Fibre-reinforced Polymer Rebar for Application in Concrete Structures, Proceedings of the Institution of Mechanical Engineers Part L, Journal of Materials Design and Applications, 2007, pp.113-119.

26. Moon, D., Sim, J., Oh, H., and Benmokrane, B., An Exploratory Study of GFRP Rebar with Ribs Containing Milled Glass Fibers, Composites: Part B, 39, 2008, pp. 882-890. 